\title{
Bladder cancer prevention
}

\author{
Anna Długosz ${ }^{1}$, Ewelina Królik ${ }^{1,2}$
}

The article discusses the most important causes of bladder cancer, related to lifestyle (smoking, diet) and exposure to carcinogenic substances, and presents available chemoprevention strategies. Based on the current state of knowledge, it enumerates the factors of proven and potential role in reducing the incidence rate of the disease.

Key words: bladder cancer, environmental factors, prevention, diet

\section{Introduction}

Bladder cancer is the most frequent urinary tract cancer and ninth among the most commonly diagnosed tumors. As many as 330,000 new cases are recorded worldwide each year and annual mortality equals 130,000 [1, 2]. Approximately 2.7 million people currently suffer from the disease [2, 3].

According to the statistics kept by the US National Cancer Institute, bladder cancer is the fifth most common cancer in the country. It is estimated that as many as 74,000 people will be diagnosed with the disease in the US in 2015 and 16,000 of these will die. Bladder cancer is usually diagnosed between the age of 75 and 84 , and affects men more frequently than women [3].

Transitional cell carcinoma (TCC) is the dominant histological type of bladder cancer; it accounts for $90 \%$ of all cases, $70 \%$ of which are benign (non-muscle-invasive bladder cancer, NMIBC), and 30\% malignant (muscle-invasive bladder cancer, MIBC) [4]. However, within 5 years from the first appearance of symptoms that suggest the presence of a tumor, approximately $40 \%$ of benign (NMIBC) cases will transition to the invasive type [5].

An important role in the development of bladder cancer is usually attributed to external risk factors. The most important among these include tobacco smoking, occupational exposure to toxins (e.g. 2-naphthylamine, 4-aminobiphenyl, 4-nitrobiphenyl, benzidine, aniline pigments, soot), and fac- tors related to diet and lifestyle (fluid intake, calorie intake, fat content in diet). A diet rich in fruits, vegetables, and polyphenols found in green tea, as well as vitamins and minerals is generally considered as a positive lifestyle factor [6, 7].

The purpose of the article is to survey the existing literature on bladder cancer prophylaxis. It proposes to discuss the main risk factors of the disease and the basic principles of prevention (Tab. I).

\section{Tobacco smoking}

Studies conducted by various teams around the world have established a clear link between smoking and an increased risk of bladder cancer; smoking status has also been shown to play an important role, with past smokers less likely to suffer from the disease. Smoking is now considered as the single most important exogenous risk factor for bladder cancer, associated with approximately $50 \%$ of all diagnosed cases [8]. The risk for smokers is around three times greater than for non-smokers, and quitting tobacco serves to reduce the likelihood of the disease by 30 to $60 \%$ within the next 4 years $[9,10]$. The number of cigarettes per day also has a significant impact on incidence rate; for those who smoke more than two packs (40 cigarettes) per day, the risk of bladder cancer is more than four times greater. Studies also suggest a correlation with smoking history (a history of 40 years and more is associated with a fivefold increase in

${ }^{1}$ Department of Toxicology, Faculty of Pharmacy with Division of Laboratory Diagnostics, Wrocław Medical University, Poland

${ }^{2}$ Department and Clinic of Internal Medicine and Allergology, Faculty of Medicine, Wrocław Medical University, Poland 
Table I. Strategies of the chemoprevention of bladder cancer

\begin{tabular}{ll}
\hline Factors with a proven role & Factors with a potential role \\
\hline Quitting cigarettes and other tobacco products & Increased intake of polyphenols \\
Reducing occupational exposure to toxins [aromatic amines and & Increased intake of clean drinking water \\
policyclic aromatic hydrocarbons (PAHs)] & Increased intake of fruits and vegetables \\
Reducing exposure to arsenic compounds in drinking water & Increased intake of vitamins A, C, E \\
Using non-steroidal anti-inflammatory drugs (NSAIDs), especially & Reduced intake of fats and high-calorie foods \\
selective cyclooxygenase-2 (COX-2) inhibitors & \\
\hline
\end{tabular}

cancer risk) and preferred cigarette type (cigarettes without filter are associated with a greater incidence rate) [11, 12]. In a study published in 2014, Wyszyński et al. emphasize the positive impact of tobacco cessation on preventing the progression or relapse of bladder cancer in previously diagnosed patients [13]. Smokers are at a greater risk of cancer because of their exposure to chemical compounds typically found in tobacco smoke, such as 4-aminobiphenyl, acrolein, and free oxygen radicals [6]. The greatest role, however, is attributed to aromatic amines. The precise mechanism through which these substances impact carcinogenesis has not been explained, but it is thought to be related to the carbocations released in the bladder during the partial hydrolysis of the products of phase II biotransformation, which are excreted in urine. Studies conducted in previous decades have confirmed their genotoxicity, showing that they are able to create DNA adducts and thus induce mutagenesis. Other (alternative or additional) carcinogenic effects of aromatic amines have also been proposed, including epigenetic mechanisms such as abnormal DNA methylation, chromatin remodeling, and histone modification [14].

\section{Occupational factors}

Occupational exposure has been the most frequently studied risk factor for bladder cancer [15]. It is estimated to account for $5.3 \%$ of all diagnosed cases and $7.1 \%$ of those found in men [16]. The most important industrial chemical compounds implicated in the process of carcinogenesis include aromatic amines (e.g. 2-naphthyloamine, 4-aminobiphenyl, 4,4'-methylenedianiline, 4-nitrobiphenyl, benzidine), PAHs (e.g. naphthalene, benzo(a)pyrene), coal tar, aniline pigments (e.g. methoxyaniline, methoxy-nitroaniline), polychlorinated dibenzodioxins, dibenzofuran, and chlorinated aliphatic hydrocarbons [7, 17, 18]. A major role is also played by metals such as arsenic, cadmium, chromium, and nickel [18]. Cumberbatch et al. performed a metaanalysis focused on the incidence of bladder cancer in various occupational groups; the data indicated a highly specific occupational profile of patients exposed to chemical carcinogens. The highest risk of bladder cancer is reported in individuals working with aromatic amines, while the highest mortality rate is observed in those exposed to PAHs and heavy metals [18]. Even though social awareness of the importance of workplace hygiene is growing and appropriate measures are being taken, the reduction of occupational exposure to carcinogenic compounds continues to be an important element of bladder cancer prevention.

\section{Environmental factors}

Arsenic is a metal that occurs naturally in water, soil, and air. Found in organic and inorganic form, it is widespread in the environment, present in more than 160 different minerals, and realeased into the air, for instance, in the process of metal ore extraction. Food produced in the vicinity of copper mines tends to be contaminated with arsenic compounds. The intensive use of arsenic-based herbicides and defoliants has also considerably contributed to environmental pollution. The carcinogenic impact of arsenic on the human body has not been fully explained but the substance is known to disrupt the homeostasis of metals and $\mathrm{SH}$ groups, negatively affect DNA methylation, cause oxidative stress, and induce cell proliferation [19]. Inorganic arsenic compounds found in potable groundwater are commonly recognized as carcinogens implicated in the development of lung and skin cancer [20], and the World Health Organization recommends that their concentration in drinking water should not exceed $10 \mu \mathrm{g} / \mathrm{L}$ [21]. Studies conducted in Argentina [22], Chile [23], USA [24], and Taiwan [25] have linked contamination with arsenic to the development of bladder cancer at concentrations of $>0.2 \mathrm{mg} / \mathrm{L}$ of drinking water [22-25].

Other factors implicated in bladder cancer also included bladder infections with Schistosoma haematobium, a major agent of schistosomiasis. Research thus far suggests that infections with the parasite are particularly common in men in developing countries, such as Turkey and Egypt [26, 27].

\section{Diet}

\section{Daily fluid intake}

The results of epidemiological studies on the relationship between fluid intake and the risk of bladder cancer thus far are inconclusive [28-32].

By increasing the frequency of urination and urine volume, large fluid intake is thought to reduce the time of contact between toxins and the walls of the bladder, thus lowering cancer risk [28]. On the other hand, drinking water and other beverages may be contaminated with potentially 
carcinogenic compounds such as arsenic or chlorination products. Consuming large quantities of such fluids increases the urine concentration of toxins; as a result, these are able to penetrate deeper into the walls of the bladder and form mutagenic DNA adducts [29, 30].

A prospective cohort study on a group of 47,909 people showed that an increased daily intake of fluids is associated with a lower risk of bladder cancer. Subjects who consumed more fluids ( $>2531 \mathrm{~mL} /$ day) were half as likely to develop bladder cancer than those who consumed less ( $<1290 \mathrm{~mL} /$ day) [30].

A study of 427 nurses also demonstrated a positive impact of high fluid intake on reducing the risk of bladder cancer in smokers (the risk dropped by $38 \%$ ), as well as lowering the likelihood of its invasive variety [29].

The European Prospective Investigation into Cancer and Nutrition (EPIC), which studied the relationship between the quantity and type of consumed fluids and the risk of bladder cancer, however, failed to establish any correlation between the two variables [31]. Wang et el., on the other hand, showed that an increase in total fluid intake correlates with a $41 \%$ increase in the risk of disease [32].

The precise role of fluid intake in bladder cancer prevention is further confounded by the diversity of beverages that may have a different impact on the processes of carcinogenesis. The most frequently listed drinks include water, tea, coffee, and alcohol [28]. Studies thus far indicate the protective effects of water, tea, wine, and milk [28, 31, 32]. Data on coffee are inconclusive. It may have a positive impact because of its high polyphenol content, but may also be harmful because of the presence of acrylamide [28, 33].

These discrepancies require further investigation.

\section{Fat intake}

Evidence concerning the relationship between the amount and type of dietary fat and the risk of bladder cancer is limited and inconclusive. This is mostly due to the lack of adequate epidemiological data. Studies conducted in the 1990s in Spain and Sweden found a direct link between the consumption of saturated fatty acids of animal origin and a greater risk of bladder cancer [34, 35]. Similar findings were obtained in Belgian studies, which also confirmed that a Mediterranean diet (rich in olive oil) plays an important role in reducing the incidence of the disease [36]. A final metaanalysis of 36 epidemiological studies demonstrated the positive impact of unsaturated vegetable fats on the reduction of bladder cancer risk [37].

\section{Fruits and vegetables}

Due to their high concentration of vitamins, minerals, fiber, and other bioactive compounds with anti-carcinogenic properties, fruits and vegetables are universally recognized as a means of preventing many types of cancer (e.g. of the stomach, liver, and intestine). Their beneficial role is related to a positive impact they exert on the immune system, their strong antioxidative properties, and their ability to reduce DNA damage associated with oxidative stress [38].

A metaanalysis published in 2014 confirmed the role of fruits and vegetables in the reduction of bladder cancer risk [39]; the findings of Park et al., however, suggest that their intake may only lower cancer incidence in women [40]. A metaanalysis performed by Xu et al. only confirmed the beneficial effects of green leafy vegetables [38]. Studies conducted by EPIC and Vieira et al., on the other hand, showed no correlation between fruit and vegetable intake and bladder cancer risk [41,42]. Because of the limited available data, further research is also required on the impact of individual fruits and vegetables.

\section{Dietary polyphenols}

Green tea is one of the most frequently consumed beverages in the world. Studies conducted on cell lines and animal models have demonstrated the strong chemoprotective properties associated with its high polyphenol content $[43,44]$. The link between green tea and the reduced risk of many cancers is common knowledge, and successive studies have confirmed its beneficial properties. Green tea contains polyphenolic compounds, such as flavanols, flavonoids, proanthocyanidins, and phenolic acids. Most of these polyphenols belong to catechins (also known as flavonols), which are the main component of green tea. Catechins present in green tea leaves include: epicatechin (EC), epicatechin gallate (ECG), epigallocatechin (EGC), and epigallocatechin gallate (EGCG), which is especially abundant [43].

In a study on animal models, green tea polyphenols were shown to inhibit the development of bladder cancer induced by a nitrosamine derivative [45]. In a study of mice with subcutaneously implanted bladder cancer cells, epigallocatechin gallate exhibited proapoptotic properties, thus impeding cancer growth. The apoptotic process in this case is thought to involve the activation of a caspase cascade regulated by proteins from the BcL-2 family [46]. A study on human bladder cancer cells also confirmed the antiproliferative properties of epigallocatechin gallate, and polyphenon 60 , epicatechin gallate, and the green tea extract were shown to have similar proapoptotic effects [44].

Zhou et al. studied the pomegranate extract (Punica granatum L.) and demonstrated the beneficial, proapoptotic impact of pomegranates on human bladder cancer cells. Not unlike in the case of green tea, these properties are linked to its high polyphenol content, which hinders cancer cell proliferation by activating the caspase cascade [47].

Literature also indicates the beneficial properties of curcumin (another polyphenol) in the prevention of bladder cancer. The mechanism involved in this case is related to the role of the spice in inducing the expression of a cytoprotective enzyme, heme oxygenase-1 [48]. 
Resveratrol, a polyphenol found especially in red grapes, is also recognized as a chemoprotective and anticarcinogenic agent. In a study by Stocco et al., high concentrations of the substance ( $>25 \mu \mathrm{M}$ ) induced the apoptosis of human bladder cancer cells (ECV304) [49].

\section{Vitamins and minerals}

Vitamins, especially vitamin A, C, and E, are well known for their anti-oxidative properties. Numerous studies thus far have shown that they likely protect cells against oxidative DNA damage by neutralizing free radicals [50]. An increased dietary intake of vitamins A, C, E also seems to have a positive impact on bladder cancer risk.

\section{Vitamin C}

Vitamin C (ascorbic acid) is an antioxidant involved in the maintenance of a healthy redox potential within cells, for instance, through the neutralization of reactive oxygen species produced during cell metabolism [51]. Shibata et al. demonstrated a positive impact of vitamin $C$ supplementation on the reduction of bladder cancer risk [52], but subsequent analyses of ascorbic acid concentrations in the blood of bladder cancer patients failed to confirm its role in the prevention of the disease $[51,52]$.

\section{Vitamin $E$}

Vitamin E consists of four tocopherols $(\alpha, \beta, \gamma, \delta)$. In the human body, its most dominant and active form is a-tocopherol, involved in neutralizing free oxygen radicals; the substance shows strong antioxidative properties, inhibiting the growth of cancer cells and stimulating their apoptosis [54]. A study published in 2008 indicated that a-tocopherol may have a protective effect in tobacco smokers [54]. Findings of various epidemiological studies also confirm the beneficial impact of vitamin E supplementation on reducing bladder cancer risk [53].

\section{Vitamin A}

Vitamin $\mathrm{A}$ and retinol (the most important among the retinoids) play a vital role in cell proliferation and differentiation [55]. Data published in 2014 indicate that an increased dietary intake of vitamin $A$ is associated with a lower incidence of bladder cancer. A significant risk reduction was associated mainly with $\alpha$-carotene, $\beta$-carotene, and $\beta$-cryptoxanthin [55]. The synthetic retinoid fenretinide (N-(4-hydroxyphenyl)retinamide) was also shown to have a protective effect in chemically induced bladder cancer in animals [56].

\section{Other factors}

Literature also indicates the beneficial effect of lycopenes found in tomato juice, linoleic acid derived from plant oils, and betulinic acid isolated from the bark of birch trees [57].
High-calorie foods and a reduced intake of selenium, on the other hand, were shown to increase the risk of the disease $[6,58]$.

Other factors that may affect the risk of bladder cancer include obesity, lack of physical exercise [59], and stress, but further research is required to establish the precise correlation.

\section{Non-steroidal anti-inflammatory drugs}

Numerous experimental, epidemiological, and clinical studies have demonstrated the important role of non-steroidal anti-inflammatory drugs (NSAIDs) in the prevention of human cancer. This is due to their inhibiting effect on the activity of cyclooxygenase-2 (COX-2), which lowers the production of prostaglandin E2 [60].

A controlled clinical study on 330 patients showed a $20 \%$ decrease in the incidence of bladder cancer among subjects treated with nonsteroidal anti-inflammatory drugs. A particularly significant risk reduction (43\%) was observed for non-smokers [61]. Experiments on mice with bladder cancer induced by N-butyl-N-(4-hydroxybutyl)nitrosamine (BNN) demonstrated that rofecoxib (a selective COX-2 inhibitor) caused a considerable decrease in the incidence of precancerous lesions and tumors [62]. The effects for meloxicam were not statistically significant [63]. The anticarcinogenic properties of meloxicam, however, were further tested on three human cell lines of bladder cancer and shown to significantly increase DNA damage in cancer cells and inhibit their proliferation [63]. The proapoptotic role of celecoxib is associated with its ability to induce the autophagy of cancer cells [64]. Other data have also shown that naproxen has a beneficial role to play in BNN-induced bladder cancer [65].

\section{Mesna (sodium 2-mercaptoethanesulfonate)}

An important factor with a clinically proven role in increasing the incidence of bladder cancer is therapy with cyclophosphamide, an immunosuppressive drug that inhibits cell division. Animal studies show that the risk of cyclophosphamide-induced bladder cancer is significantly lower when the treatment is accompanied by the administration of Mesna (sodium 2-mercaptoethanesulphonate) [66].

\section{Detoxification processes}

Considering the role of chemical risk factors in the development of bladder cancer, it is crucial to take preventive measures to increase the body's ability to detoxify. Toxic elements are largely excreted in urine, following the reactions of phase I and II biotransformation, which means that inducing phase II enzymes, such as glutathione S-transferase (GST), or glutamylcysteine synthetase (GCS) may have a beneficial, protective role to play in the prevention of bladder cancer. 
The gene polymorphism of glutathione S-transferase (GST) may determine individual susceptibility to bladder cancer. The risk of disease has been shown to be four times greater in individuals with the homozygotic variant of the GSTP1 Val/Val genotype [67]. A metaanalysis published by Huang et al. confirmed an important increase in cancer risk in people with the GSTP1 313A>G polymorphism [68].

And thus, from the toxicological point of view, an important role in the prevention of bladder cancer is played by a specific pool of endogenous compounds that participate in phase II detoxification reactions, the activity of selected enzymes, and the participation of high-energy compounds (e.g. ATP) necessary for activating the endogenous substances that enable their conjugation.

\section{Conclusions}

Bladder cancer is one of the more frequent urinary tract conditions and its development, alongside genetic determinants, is largely related to exogenous factors. Identifying these variables allows us to successfully eliminate them and thus prevent the incidence of new cases. Examples cited in this paper demonstrate the crucial importance of quitting tobacco and reducing exposure to carcinogenic substances (such as aromatic amines, polycyclic aromatic hydrocarbons, and arsenic). A healthy diet, especially rich in polyphenols such as epigallocatechin, curcumin, and resveratrol, is equally crucial in cancer prevention. It is essential to drink a lot of fluids, preferably water or green tea, reduce the intake of high-calorie, fatty foods, consume more fruits and vegetables rich in antioxidants, and make sure to supplement potential vitamin $\mathrm{A}$ and $\mathrm{E}$ deficiencies.

An important chemoprotective role is also played by nonsteroidal anti-inflammatory drugs; selective COX-2 inhibitors are particularly effective in this respect, but their toxicity means they can only be administered under strict medical supervision.

In light of the growing incidence rate of bladder cancer, it is crucial to take measures to protect the environment, reduce the concentrations of carcinogenic substances in air, drinking water, and food, as well as to use agents that boost the immune system, promote detoxification, and improve the state of the urothelium (the membrane that lines the bladder).

\section{List of abbreviations}

NMIBC - non-muscle-invasive bladder cancer

$\mathrm{PAH}$ - polycyclic aromatic hydrocarbons

WHO - World Health Organization

BNN - N-butyl-N-(4-hydroxybutyl)nitrosamine

Mesna - sodium 2-mercaptoethanesulfonate, a secretolytic drug from the mucolytic group

GSTP1 — glutathione S-transferase P1 gene

COX-2 - cyclooxigenase-2
Conflict of interest: none declared

\section{Anna Długosz, PhD}

Department of Toxicology

Faculty of Pharmacy with the Division of Laboratory Diagnostics

Wrocław Medical University

Borowska St. 211

50-556 Wrocław, Poland

e-mail:anna.dlugosz@umed.wroc.pl

Received: 20 Jun 2016

Accepted: 30 Jan 2017

\section{References}

1. Roupêrt M, Babjuk M, Compérat E et al. European Association of Urology Guidelines on Upper Urinary Tract Urothelial Cell Carcinoma: 2015 Update. Eur Urol 2015; 68: 868-879.

2. Ploeg M, Aben KK, Kiemeney LA. The present and future burden of urinary bladder cancer in the world. World J Urol 2009; 27: 289-293.

3. http://www.cancer.gov (07.01.2016).

4. Gui Y, Guo G, Huang Y et al. Frequent mutations of chromatin remodeling genes in transitional cell carcinoma of the bladder. Nat Genet 2011; 43: 875-878.

5. Sylvester RJ. Natural history, recurrence, and progression in superficial bladder cancer. Scientific World J 2006; 6: 2617-2625.

6. Leppert JT, Shvarts O, Kawaoka K et al. Prevention of bladder cancer: a review. Eur Urol 2006; 49: 226-234.

7. Letašiová S, Medved'ová A, Šovčíková A et al. Bladder cancer, a review of the environmental risk factors. Env Health 2012; 11(Suppl 1): S11.

8. Freedman ND, Silverman DT, Hollenbeck AR et al. Association between smoking and risk of bladder cancer among men and woman. JAMA 2011; 306: 737-745.

9. National Collaborating Centre for Cancer (UK). Bladder cancer: diagnosis and management. NICE Guideline, 2015 (2.4: 72-77).

10. Rink M, Crivelli JJ, Shariat SF et al. Smoking and bladder cancer: a systematic review of risk and outcomes. Eur Urol Focus 2015; 1: 17-27.

11. Zheng YL, Amr S, Saleh DA et al. Urinary bladder cancer risk factors in Egypt: a multicenter case-control study. Cancer Epidemiol Biomarkers Prev 2012; 21: 537-546.

12. Erdurak K, Dundar PE, Ozyurt BC et al. Smoking, occupation, history of selected diseases and bladder cancer risk in Manisa, Turkey. Eur $J$ Cancer Prev 2014; 23: 58-61.

13. Wyszynski A, Tanyos SA, Rees JR et al. Body mass and smoking are modifiable risk factors for recurrent bladder cancer. Cancer 2014; 120:408-414.

14. Besaratina A, Tommasi S. Genotoxicity of tobacco smoke-derived aromatic amines and bladder cancer: current state of knowledge and future research directions. FASEB J 2013; 27: 2090-2100.

15. Reulen RC, Kellen E, Buntinx F et al. A meta-analysis on the association between bladder cancer and occupation. Scand J Urol Nephrol Suppl 2008; 42 (Suppl 218): 64-78.

16. Rushton L, Bagga $S$, Bevan R et al. Occupation and cancer in Britain BrJ Cancer 2010; 102: 1428-1437.

17. Wu X, Ros MM, Gu J et al. Epidemiology and genetic susceptibility to bladder cancer. BJU Int 2008; 102: 1207-1215.

18. Cumberbatch MG, Cox A, Teare D et al. Contemporary occupational carcinogen exposure and bladder cancer: a systematic review and meta-analysis. JAMA Oncol 2015; 1: 1282-1290.

19. Hughes MF. Arsenic toxicity and potential mechanisms of action. Toxicol Lett 2002; 133: 1-16.

20. Cheng PS, Weng SF, Chiang CH et al. Relationship between arsenic-containing drinking water and skin cancers in the arseniasis endemic areas in Taiwan. J Dermatol 2016; 43: 181-186.

21. WHO guidelines for drinking-water quality. Arsenic in drinking-water. WHO/SDE/WSH/03.04/75/Rev/1.

22. Bates MN, Rey OA, Biggs ML et al. Case-control study of bladder cancer and exposure to arsenic in Argentina. Am J Epidemiol 2004; 159: 381-389.

23. Marshall G, Ferreccio C, Yuan $Y$ et al. Fifty-year study of lung and bladder cancer mortality in Chile related to arsenic in drinking water. $J \mathrm{NCl}$ 2007; 99: 920-928.

24. Steinmaus C, Yuan Y, Bates MN et al. Case-control study of bladder cancer and drinking water arsenic in the western United States. Am J Epidemiol 2003; 158: 1193-1201. 
25. Długosz A, Gąsior J, Guzik A. Wpływ czynników środowiskowych na rozwój raka pęcherza moczowego. Nowotwory J Oncol 2015; 65: 35-41.

26. Bedwani R, Renganathan E, El Kwhsky F et al. Schistosomiasis and the risk of bladder cancer in Alexandria, Egypt. Br J Cancer 1998; 77: 1186-1189.

27. Mostafa MH, Sheweita SA, O'Connor PJ. Relationship between schistosomiasis and bladder cancer. Clin Microbiol Rev 1999; 12: 97-111.

28. Bai Y, Yuan H, Li J et al. Relationship between bladder cancer and total fluid intake: a meta-analysis of epidemiological evidence. World J Surg Oncol 2014; 12: 223.

29. Zhou J, Kelsey KT, Giovannucci E et al. Fluid intake and risk of bladder cancer in the Nurses'Health Studies. Int J Cancer 2014; 135: 1229-1237.

30. Zhou J, Smith S, Giovannucci E et al. Reexamination of total fluid intake and bladder cancer in the health professionals follow-up study cohort. Am J Epidemiol 2012; 175: 696-705.

31. Ros MM, Bas Bueno-de-Mesquita HB, Büchner FL et al. Fluid intake and the risk of urothelial cell carcinomas in the European Prospective Investigation into Cancer and Nutrition (EPIC). Int J Cancer 2011; 128: 2695-2708.

32. Wang J, Wu X, Kamat A et al. Fluid intake, genetic variants of UDP-gucuronosyltransferases, and bladder cancer risk. Br J Cancer 2013; 108: 2372-2380.

33. Wierzejska R. Coffee consumption vs. cancer risk - a review of scientific data. Rocz Państw Zakł Hig 2015; 66: 293-298.

34. Riboli E, Gonzáles CA, López-Abente G et al. Diet and bladder cancer in Spain: a multi-centre case-control study. Int J Cancer 1991;49: 214-219.

35. Steineck G, Hagman U, Gerhardsson M et al. Vitamin A supplements, fried foods, fat and urothelial cancer. A case-referent study in Stockholm in 1985-87. Int J Cancer 1990; 45: 1006-1011.

36. Brinkman MT, Buntinx F, Kellen E et al. Consumption of animal products, olive oil and dietary fat and results from the Belgian case-control study on bladder cancer risk. Eur J Cancer 2011; 47: 436-442.

37. Steinmaus $\mathrm{CM}$, Nuňez S, Smith AH. Diet and bladder cancer: a meta-analysis of six dietary variables. Am J Epidemiol 2000; 151: 693-702.

38. Xu C, Zeng XT, Liu TZ et al. Fruits and vegetables intake and risk of bladder cancer. Medicine 2015; 94: 1-12.

39. Yao B, Yan Y, Ye X et al. Intake of fruits and vegetables and risk of bladder cancer: a dose-response meta-analysis of observational stusies. Cancer Causes Control 2014; 25: 1645-1658.

40. Park SY, Ollberding NJ, Woolcott CG et al. Fruit and vegetable intakes are associated with lower risk of bladder cancer among women in the Multiethnic Cohort Study. J Nutr 2013; 143: 1283-1292.

41. Bradbury KE, Appleby PN, Key TJ. Fruit, vegetable and fiber intake in relation to cancer risk: findings from the European Prospective Investigation into Cancer and Nutrition (EPIC). Am J Clin Nutr 2014; 100 Suppl 1: 394S-398S

42. Vieira AR, Vingeline $S, C$ Chan DS et al. Fruits, vegetables, and bladder cancer risk: a systematic review and meta-analysis. CancerMed 2015;4: 136-146.

43. Całka J, Zasadowski A, Juranek J. Niektóre aspekty leczniczego działania zielonej herbaty. Bromat Chem Toksykol 2008; 1: 5-14.

44. Philips BJ, Coyle CH, Morrisroe SN et al. Induction of apoptosis in human bladder cancer cells by green tea catechins. Biomed Res 2009;30:207-215.

45. Sagara $Y$, Miyata $Y$, Nomata $\mathrm{K}$ et al. Green tea polyphenol suppresses tumor invasion and angiogenesis in N-butyl-(-4-hydroxybutyl)nitrosamine-induced bladder cancer. Cancer Epidemiol 2010; 34: 350-354.

46. Hsieh DS, Wang $\mathrm{H}$, Tan SW et al. The treatment of bladder cancer in a mouse model by epigallocatechin-3-gallategold nanoparticles. Biomaterials 2011; 32: 7633-7640.
47. Zhou B, Yi H, Tan J et al. Anti-proliferative effects of polyphenols from pomegranate rind (Punica granatum L.) on EJ bladder cancer cells via regulation of p53/miR-34a axis. Phytother Res 2015; 29: 415-422.

48. Wu SY, Lee YR, Huang CC et al. Curcumin-induced heme oxygenase-1 expression plays a negative role for its anti-cancer effect in bladder cancers. Food Chem Toxicol 2012; 50: 3530-3536.

49. Stocco B, Toledo K, Salvador M et al. Dose-dependent effect of resveratrol on bladder cancer cells: chemoprevention and oxidative stress. Maturitas 2012; 72: 72-78.

50. Guz J, Dziaman T, Szpila A. Czy witaminy antyoksydacyjne mają wpływ na proces karcynogenezy? Postepy Hig Med Dośw 2007; 61: 185-198.

51. Konopacka M. Rola witaminy C w uszkodzeniach oksydacyjnych DNA. Postepy Hig Med Dośw 2004; 58: 343-348.

52. Shibata A, Paganini-Hill A, Ross RK et al. Intake of vegetables, fruits, beta-carotene, vitamin $C$ and vitamin supplements and cancer incidence among the elderly: a prospective study. Br J Cancer 1992; 66: 673-679.

53. Chen F, Li Q, Yu Y et al. Association of vitamin C, vitamin D, vitamin E and risk of bladder cancer: a dose-response meta-analysis. Sci Rep 2015; 5: 9599.

54. Liang D, Lin J, Grossman HB et al. Plasma vitamins E and A and risk of bladder cancer: a case-control analysis. Cancer Causes Control 2008; 19:981-992.

55. Tang J, Wang R, Zhong H. et al. Vitamin A and risk of bladder cancer: a meta-analysis of epidemiological studies. World J Surg Oncol 2014; 12:130.

56. Alizadeh F, Bolhassani A, Khavari A et al. Retinoids and their biological effects against cancer. Int Immunopharmacol 2014; 18: 43-49.

57. Chung KT. The etiology of bladder cancer and its prevention. J Cancer Sci Ther 2013; 5: 346-361.

58. Beane Freeman LE, Karagas MR, Baris D et al. Is the inverse association between selenium and bladder cancer due to confounding by smoking? Am J Epidemiol 2015; 181: 488-495.

59. Noguchi JL, Liss MA, Parsons JK. Obesity, physical activity and bladder cancer. Curr Urol Rep 2015; 16: 74.

60. Kmieć N, Wełnicka-Jaśkiewicz M, Jassem J. Niesteroidowe leki przeciwzapalne w profilaktyce i leczeniu nowotworów jelita grubego. Nowotwory J Oncol 2014; 64: 175-179.

61. Blumentals WA, Foulis PR, Schwartz SW et al. Analgesic therapy and the prevention of bladder cancer. Urol Oncol 2004; 22: 11-15.

62. D'Arca D, LeNoir J, Wildemore B et al. Prevention of urinary bladder cancer in the FHIT knock-out mouse with Rofecoxib, a Cox-2 inhibitor. Urol Oncol 2010; 28: 189-194.

63. Arantes-Rodrigues R, Pinto-Leite R, Ferreira R et al. Meloxicam in the treatment of in vitro and in vivo models of urinary bladder cancer. Biomed Pharmacother 2013; 67: 277-284.

64. Huang KH, Kuo KL, Ho IL et al. Celecoxib-induced cytotoxic effect is potentiated by inhibition of autophagy in human urothelial carcinoma cells. PLoS One 2013; 8: e.82034.

65. Nicastro HL, Grubbs $\mathrm{CJ}$, Juliana MM et al. Preventive effects of NSAIDs, NO-NSAIDs, and NSAIDs plus Difuoromethylornithine in a chemically induced urinary bladder cancer model. Cancer Prev Res 2014; 7:246-254.

66. Griffiths TR; Action on bladder cancer. Current perspectives in bladder cancer management. Int J Clin Pract 2013; 67: 435-448.

67. Safarinejad MR, Safarinejad S, Shafiei N et al. Association of genetic polymorphism of glutathione S-transferase (GSTM1, GSTT1, GSTP1) with bladder cancer susceptibility. Urol Oncol 2013; 31: 1193-1203.

68. Huang SX, Wu FX, Luo M et al. The glutathione S-transferase P1 341C>T polymorphism and cancer risk: a meta-analysis of 28 case-control studies. PloS One 2013; 8: e.56722. 